\title{
Stillbirths: Recall to action in high-income countries
}

\subsection{Authors}

Vicki Flenady ${ }^{\mathrm{PhD}}$, Aleena M Wojcieszek ${ }^{\text {BPsysci }}$, Philippa Middleton ${ }^{\text {PhD }}$, David Ellwood ${ }^{\text {PhD }}$, Jan Jaap Erwich $^{\text {PhD }}$, Michael Coory ${ }^{\text {PhD }}$, T Yee Khong ${ }^{\mathrm{MD}}$, Robert M Silver ${ }^{\text {PhD }}$, Gordon Smith ${ }^{\text {DSc }}$, Frances M Boyle ${ }^{\text {PhD }}$, Joy E Lawn ${ }^{\text {PhD }}$, Hannah Blencowe ${ }^{\text {MRCPCH}}$, Susannah Hopkins Leisher ${ }^{\text {MA }}$, Mechthild M Gross ${ }^{\text {PhD, Dell }}$ Horey ${ }^{\text {PhD }}$, Lynn Farrales ${ }^{\text {MD }}$, Frank Bloomfield ${ }^{\text {PhD }}$, Lesley McCowan ${ }^{\text {MD }}$, Stephanie J Brown ${ }^{\text {PhD }}$, K S Joseph $^{\text {PhD }}$, Jennifer Zeitlin ${ }^{\mathrm{DSC}}$, Hanna E Reinebrant ${ }^{\mathrm{PhD}}$, Claudia Ravaldi ${ }^{\mathrm{MD}}$, Alfredo Vannacci ${ }^{\text {PhD }}$, Jillian

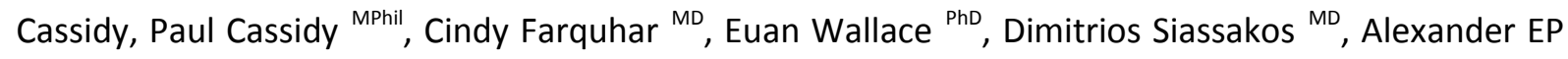
Heazell ${ }^{\text {hhD }}$, Claire Storey ${ }^{\text {BA }}$, Lynn Sadler ${ }^{\mathrm{MPH}}$, Scott Petersen ${ }^{\mathrm{MBBS}}$, J Frederik Frøen ${ }^{\text {PhD }}$, Robert L Goldenberg ${ }^{\mathrm{MD}}$

\subsection{The Lancet Ending Preventable Stillbirths study group}

J Frederik Frøen, Joy E Lawn, Hannah Blencowe, Alexander Heazell, Vicki Flenady, Luc de Bernis, Mary Kinney, Susannah Hopkins Leisher

\subsection{Author affiliations}

Mater Research Institute - The University of Queensland (MRI-UQ), Brisbane, Australia (V Flenady, A M Wojcieszek, S Hopkins Leisher, D Horey, H Reinebrant, S Petersen); International Stillbirth Alliance (V Flenady, A M Wojcieszek, P Middleton, D Ellwood, J Erwich, M Coory, T Y Khong, R M Silver, F M Boyle, S Hopkins Leisher, H Reinebrant, L Farrales, L McCowan, C Ravaldi, A Vannacci, J Cassidy, P Cassidy, E Wallace, D Sisassakos, A Heazell, C Storey); Women's \& Children's Health Research Institute (WCHRI), The University of Adelaide, Adelaide, Australia (P Middleton); Griffith University \& Gold Coast University Hospital, Gold Coast, Australia (D Ellwood); The University of Groningen, University Medical Center Groningen, Groningen, The Netherlands (J Erwich); Murdoch Childrens Research Institute, Melbourne, Australia (M Coory); SA Pathology, University of Adelaide, Adelaide, Australia (T Y Khong); University of Utah Health Sciences Center, United States (R M Silver); NIHR Biomedical Research Centre \& Cambridge University, United Kingdom (G Smith); The University of Queensland, Brisbane, Australia (F M Boyle); London School of Hygiene and Tropical Medicine, London, United Kingdom (J E Lawn, H Blencowe); Hannover Medical School, Hannover, Germany; Zurich University of Applied Sciences, Institute for Midwifery, Winterthur, Switzerland (M M Gross); La Trobe University, Melbourne, Australia (D Horey); Still Life Canada: Stillbirth and Neonatal Death Education, Research and Support Society, Canada (L Farrales); Liggins Institute, The University of Auckland, Auckland, New Zealand (F Bloomfield); The University of Auckland, Auckland, New Zealand 
(L McCowan, C Farquhar, L Sadler); Murdoch Childrens Research Institute and General Practice and Primary Health Care Academic Centre, The University of Melbourne, Parkville, Australia, S J Brown); University of British Columbia, Vancouver, Canada (L Farrales, K S Joseph); INSERM, Obstetrical, Perinatal and Paediatric Epidemiology Research Team, Centre for Epidemiology and Biostatistics (U1153), Paris-Descartes University, Paris, France (J Zeitlin); CiaoLapo Onlus - Charity for High-Risk Pregnancies and Perinatal Grief Support, Italy (C Ravaldi; A Vannacci); Department of Neurosciences, Psychology, Drug Research and Child Health, University of Florence, Italy (A Vannacci); Umamanita, Spain (J Cassidy, P Cassidy); Monash University, Melbourne Australia (E Wallace); University of Bristol; Southmead Hospital, Bristol, UK (D Siassakos); University of Manchester, UK; St. Mary's Hospital, Central Manchester University Hospitals NHS Foundation Trust, Manchester Academic Health Science Centre, Manchester, (A Heazell); Mater Health Services, Brisbane, Australia (S Petersen); Department of International Public Health, Norwegian Institute of Public Health, Oslo, and Center for Intervention Science for Maternal and Child Health, University of Bergen, Norway (J F Frøen ); Department of Obstetrics and Gynecology, Columbia University, New York, USA (RL Goldenberg)

\subsection{The Lancet stillbirths in high-income countries investigator group}

Bia Bichara (London School of Hygiene \& Tropical Medicine, London, UK); Beatrice Blondel (National Institute of Health and Medical Research (INSERM), Paris, France); Sheelagh Bonham (Healthcare Pricing Office (HPO), Ireland); Stephanie Bradley; Joanne Cacciatore (Arizona State University, Tempe, USA); Andre Carvalho (Sands Australia); Paul Corcoran (National Perinatal Epidemiology Centre, University College Cork, Ireland); Vicki Culling (Sands Wellington-Hutt Valley, New Zealand); Jane Dahlstrom (Australian National University, Canberra, Australia; International Stillbirth Alliance); Soo Downe (ReaCH group, University of Central Lancashire, UK); Christine East (Monash University \& Monash Health, Melbourne, Australia; International Stillbirth Alliance); Mairie Cregan (Feillecain, Ireland; International Stillbirth Alliance); Robin Cronin (The University of Auckland, Auckland, New Zealand); Francine de Montigny (Université du Québec en Outaouais, Gatineau, Canada); Sabine de Wall (Hannover Medical School, Hannover, Germany); Elizabeth Draper (MBRRACE-UK, Dept of Health Sciences, University of Leicester, Leicester, UK); Wes Duke (U.S. Department of Health and Human Services, Washington, USA; International Stillbirth Alliance); Alison Ellis (The University of Bristol, Bristol, UK); Jane P Fox (Mater Research Institute - The University of Queensland (MRI-UQ), Brisbane, Australia); Ruth C Fretts (Harvard Vanguard Medical Associates, Wellesley, USA; International Stillbirth Alliance); Stephanie Fukui (SIDS Family Association, Japan); Glenn Gardener (Mater Health Services, Brisbane, Australia; International Stillbirth Alliance); Kristen Gibbons (Mater Research Institute - The University of Queensland (MRI-UQ), Brisbane, Australia); Katherine J Gold 
(Department of Family Medicine and Department of Obstetrics, University of Michigan, Ann Arbor, USA; International Stillbirth Alliance); Sanne Gordijn (The University of Groningen, University Medical Center Groningen, Groningen, The Netherlands; International Stillbirth Alliance); Adrienne Gordon (The University of Sydney, Sydney, Australia); Grace Guyon (Alberta Health Services Perinatal Program, Alberta Canada); Ibinabo Ibiebele (Mater Research Institute - The University of Queensland (MRI-UQ), Brisbane, Australia); Belinda Jennings (International Stillbirth Alliance); Alison Kent (Australian National University Medical School \& Centenary Hospital for Women and Children, Canberra, Australia; International Stillbirth Alliance); Sue Kildea (Mater Health Service, Mater Research Institute, University of Queensland (MRI-UQ) \& School of Nursing, Midwifery and Social Work, UQ); Fleurisca Korteweg (The University of Groningen, Martini Hospital, Groningen, The Netherlands; International Stillbirth Alliance); Tina Lavender; Rohan Lourie (Mater Health Services, Brisbane, Australia); Brad Manktelow (MBRRACE-UK, Dept of Health Sciences, University of Leicester, Leicester, UK); Vicki Masson (The University of Auckland, Auckland, New Zealand); Elizabeth McClure (Research Triangle Institute, NC, USA; International Stillbirth Alliance); Sarah Meaney (National Perinatal Epidemiology Centre, University College Cork, Ireland); Kelly Merchant (Bears of Hope, Australia); Susan McDonald (La Trobe University \& Mercy Hospital for Women, Melbourne, Australia; International Stillbirth Alliance); Margaret Murphy (University College Cork, Ireland; International Stillbirth Alliance); Jeremy Oats (University of Melbourne, Melbourne, Australia; International Stillbirth Alliance); Karin Pettersson (Karolinska University Hospital, Stockholm, Sweden; International Stillbirth Alliance); Ingela Rådestad (Sophiahemmet University, Stockholm, Sweden; International Stillbirth Alliance); Leanne Raven (SIDS and Kids, Australia); Uma Reddy (Eunice Kennedy Shriver National Institute of Child Health and Human Development, Rockville, USA); Jessica Ruidiaz (Fundación Era en Abril; International Stillbirth Alliance); Anne Schirmann (The University of Queensland, Brisbane, Australia); Janet Scott (SANDS UK; International Stillbirth Alliance); Lucy Smith (MBRRACE-UK, Dept of Health Sciences, University of Leicester, Leicester, UK); William Stones (The University of St Andrews, Scotland, UK; FIGO); Scotland, UK); Anna Usynina (Northern State Medical University, Arkhangelsk, Russia); Susanne van Gogh (Zurich University of Applied Sciences, Institute for Midwifery, Winterthur, Switzerland); Susan P Walker (The University of Melbourne, Melbourne, Australia; International Stillbirth Alliance); Patricia Wilson (Mater Health Services, Brisbane, Australia; International Stillbirth Alliance).

\subsection{Correspondence to}

Associate Professor Vicki Flenady, Mater Research Institute - The University of Queensland (MRI-UQ), Level 3 Aubigny Place, Mater Health Services, South Brisbane, QLD, Australia vicki.flenady@mater.uq.edu.au 


\subsection{Abstract}

Variation in stillbirth rates across high-income countries (HIC) and large equity gaps within HIC persist. If all HIC achieved stillbirth rates equal to the best performing countries, 19,439 late gestation stillbirths could have been avoided in 2015. Unexplained stillbirths remain high and can be addressed through improvements in data collection, investigation and classification, and better understanding of causal pathways. Substandard care contributes to $20-30 \%$ of all stillbirths, and the contribution is even higher for late-gestation intrapartum stillbirths. National perinatal mortality audit programmes need to be implemented across all HIC. Reducing stigma and fatalism around stillbirth and improving bereavement care are also clear, ongoing priorities for action. In HIC, a child has twice the risk of being stillborn due to adverse socioeconomic circumstances. Community- and country-level programs to improve health among disadvantaged families are needed to address these inequities.

\subsection{Key words}

Stillbirth; Perinatal mortality; High-income countries; Quality of care; Implementation; Perinatal audit; Classification; Bereavement care 


\subsection{Key messages}

- Late gestation stillbirth rates vary across HIC from 1.3 to $8.8 / 1000$ births, showing that further reduction in stillbirths is possible. Setting and monitoring targets in all HIC are important for reducing preventable stillbirths.

- Socially marginalised and disadvantaged women often have twice or more the risk of stillbirth. Social determinants of maternal and fetal wellbeing should be monitored in all HIC, and addressed through education and alleviation of poverty, as well as better access to health care, especially timely, culturally appropriate antenatal care.

- Stigma and fatalism continue to exacerbate trauma for families and impede progress in stillbirth prevention. Stronger parent and care provider partnerships are needed to dispel misperceptions and negative attitudes that persist in communities.

- It is the responsibility of all countries to implement high quality national perinatal mortality audit that translates into improvements in quality of care. Key performance indicators of quality maternity care should be measured and reported, with the aim of eliminating substandard antepartum and intrapartum care - too often present when a stillbirth occurs.

- Bereavement care commonly fails to meet the needs of parents, often with devastating consequences. Immediate bereavement care should be provided by appropriately trained health care professionals with sensitive and seamless transition to community support services in all settings.

- Poor quality data on stillbirths is a major problem across HIC. Access to high quality investigation into the causes of stillbirth, including autopsy and placental histopathology by a skilled perinatal pathologist, should be made available to all parents following stillbirth. Consensus on a classification system for stillbirth, which addresses the contribution of placental pathology, and standard a definition for reporting stillbirths that makes it possible to report comparable early and late stillbirth rates across HIC are needed.

- Future research must focus on stillbirth prediction, understanding placental pathways to stillbirth and causal pathways to unexplained stillbirth. Effective strategies to reduce the prevalence of obesity and smoking in women of reproductive ages are needed. Understanding pathways leading to early stillbirth and spontaneous preterm birth at early gestation is also important to pursue. 


\subsection{Introduction}

As stated across this Series, stillbirth rate is a key indicator of women's health and quality of care in pregnancy and childbirth. ${ }^{1,2}$ While high income country (HIC) rates are relatively low compared with low- and middle-income countries (LMIC), stillbirth is a major health burden with rates over double neonatal mortality rates, ${ }^{3}$ and often equal to all deaths in the first year. ${ }^{4}$ Neonatal death rates continue to fall, ${ }^{4}$ whereas stillbirth rates remain steady, and have increased in some regions. ${ }^{5}$ The death of any child is a tragedy for families, often with profound, long-lasting psychosocial and economic impact. ${ }^{6}$ The 2011 Lancet Stillbirth Series (LSS) drew attention to the slow progress in reducing rates across $\mathrm{HIC}$ and highlighted prevention. ${ }^{7}$ In this fourth paper of the Lancet's Ending Preventable Stillbirths series, we summarise the current status of stillbirths in HIC, and present strategies to maintain momentum in reducing deaths and meeting parents' needs when their child is stillborn.

\subsection{Methods}

We used the range of methods described in Panel 1 with further details provided in the webappendix. We also assessed HIC stillbirth rates and annual rate reductions (ARR) from 2000 to 2015 (Blencowe and colleagues). ${ }^{8}$

\subsection{Stillbirth rates - Is progress good enough?}

The latest global estimates ${ }^{8}$ show an average stillbirth rate (using the 28 weeks' gestation definition) across 49 HIC of 3.5 per 1000 total births. Country-specific rates varied widely from 1.3 to 8.8 (Figure 1). The ARR from 2000 to 2015 varied, with nine countries demonstrating ARRs of $<1 \%$, and five countries $>4 \%$. Cross-country comparisons are hindered by data capture issues including reporting practices for termination of pregnancy after the gestational age threshold, variation in data capture mechanisms including the use of cross-linkages between birth and death certificate data and birth registry data, and variation in definitions for reporting. ${ }^{8}$ Use of the WHO recommended lower gestational age limit of 28 weeks likely reduces the influence of these issues on reported rates. Regardless of data capture issues, real epidemiological variation in rates is present, ${ }^{9}$ and shows 
further reduction is possible. Stillbirth rates for disadvantaged groups are around double those of greater advantage, ${ }^{3,10-12}$ with recent evidence indicating these gaps can be narrowed. ${ }^{10}$ While intrapartum stillbirths comprise a small proportion $(<10 \%)$ across HIC, variability in this indicator is also evident, as presented by Lawn and colleagues. ${ }^{9}$ Nonetheless, it is important that countries monitor and understand their own temporal trends rather than assess performance based on rankings with other countries.

As shown in Figure 1, 6 of 49 countries (12\%) demonstrated third trimester rates of 2.0/1000 births or lower, showing that this is achievable. If all countries had achieved a stillbirth rate $\leq 2.0$, in 2015, 19,439 late gestation stillbirths could have been avoided.

\subsubsection{Early gestation stillbirth}

Depending on definition, $35 \%{ }^{13}$ to $50 \%{ }^{14}$ of HIC stillbirths occur below the WHO recommended cutoff for international comparison of $1000 \mathrm{~g}$ (or 28 weeks). ${ }^{13}$ Due to variability in definitions (e.g. inclusion of terminations), comparisons of early gestation stillbirth rates between and even within countries are difficult. When crude stillbirths rates were compared, Sweden ranked $3^{\text {rd }}$ and Australia $28^{\text {th }}$ in a comparison of $28 \mathrm{HICs}$, but Sweden dropped to $10^{\text {th }}$ and Australia improved to $11^{\text {th }}$ when rank was based on stillbirths $\geq 1000 \mathrm{~g} .{ }^{15}$ Under-reporting of stillbirths $<28$ weeks is also evident in some regions. ${ }^{3}$ Ascertainment may be influenced by perceptions of viability. ${ }^{8}$ Despite these difficulties, stillbirth rates $<28$ weeks' in HIC are not falling, and some increases are evident. ${ }^{5,13,14,16}$ In Canada, pregnancy terminations for congenital anomalies at 20-23 weeks gestation explain the increasing stillbirth rate..$^{5}$ In the USA, spontaneous preterm birth at early gestations made a significant contribution to higher stillbirth rates in black non-Hispanic women. ${ }^{17}$ Thus, in HIC, stillbirths at $<28$ weeks comprise an important component of all adverse pregnancy outcomes, particularly among some racial/ethnic groups.

\subsubsection{Perceptions of stillbirth - Are they holding back progress?}

Fatalism and stigma around stillbirth persist in HIC, both across communities and in the healthcare workforce (as reported in the LSS). ${ }^{18}$ In the International Stillbirth Alliance (ISA) surveys (see Panel 1 
for methods), 2 in 3 respondents felt their community believed that most stillbirths are not preventable (Figure 2). Around 1 in 2 parents felt their community believed that "parents should not talk about their stillborn baby because it makes people feel uncomfortable". One parent said "...many women told me that my son's death was likely 'nature taking care of mistakes'". Perceptions and actions that denigrate grief, dismiss the significance of a stillborn child, or support notions that a child was "never supposed to live", are harmful to bereaved parents and devalue efforts towards

prevention. ${ }^{18}$ Parent organisations provide powerful mechanisms to challenge stigma and fatalism around stillbirth ("Parents bringing about change", webappendix).

\subsection{Factors leading to stillbirth}

\subsubsection{Risk factors - Are we sufficiently aware?}

Risk factors including demographic and lifestyle factors and medical/pregnancy conditions were reported in the LSS ${ }^{7}$. In the ISA survey of care providers, we asked respondents to select 10 out of 23 risk factors and associated conditions they believed posed the highest risk. We present the survey rankings alongside the adjusted odds ratio (aOR) as reported in the $\mathrm{LSS}^{19}$ and recent systematic reviews (Figure 1, webappendix) ${ }^{20-22}$ Perceptions were generally consistent with the evidence, but care providers underestimated of the risks of advanced maternal age ( $>35$ years), IVF, and multiple gestations, and overestimated of the risk of preeclampsia, smoking and substance misuse.

Risks associated with maternal obesity were also underestimated. In the survey of community members, $72 \%(n=1113)$ rated community awareness of overweight and obesity as very low to moderate (Figure 2, webappendix). With increasing prevalence of overweight and obesity, interventions to increase the number of women beginning pregnancy with a normal body weight are critically important to improving pregnancy outcomes and longer-term health. Modelling of a large Canadian cohort indicates a $10 \%$ decrease in pregnancy BMI could decrease stillbirth risk by $10 \%{ }^{23}$ However, targeting behavioural change alone fails to recognise the complexity of this problem, resulting in ineffective interventions and added stigma for women who are overweight. ${ }^{24}$ Antenatal 
care that "problematises" women by focusing on weight rather than a healthy pregnancy can produce feelings of embarrassment, guilt and shame, ${ }^{25,26}$ leading women to avoid or delay care.

\subsubsection{Classification of causes - Where do we need to focus?}

Despite the call in the LSS for a uniform approach to the definition and classification of stillbirths, ${ }^{27}$ a recent systematic review of causes of stillbirth globally ${ }^{28}$ showed continued use of disparate approaches across HIC (Table 4, webappendix), rendering interpretation difficult. Despite this, placental pathologies were clearly important, accounting for around $50 \%$ of stillbirths in systems designed to capture them. Wide variation was shown in capture and definition of these pathologies, consistent with a recent review. ${ }^{29}$ The contribution of other important factors varied widely; congenital abnormalities ranged from 6-33\%; infection 2-22\%; and spontaneous preterm birth/preterm ruptured membranes (PROM) 1-14\%. In one high quality study, spontaneous preterm birth/PROM was a key factor in $41 \%$ of stillbirths $<28$ weeks. ${ }^{17}$

Studies using hierarchical approaches showed higher proportions of $\mathrm{FGR}^{30}$ and congenital abnormalities, ${ }^{11,14}$ depending on the system used. The categories "Other unspecified" and "Unexplained" showed the widest variation and highest proportions; up to $76 \%$ and $53 \%$ respectively.

\subsubsection{Diagnostic tests for finding the cause of stillbirth}

The evidence for many routinely performed stillbirth investigations is limited. While ongoing studies in the Netherlands and Australia will help to address this, the value of placental histopathology, autopsy, and genetic analysis is clear. ${ }^{31,32}$ Nonetheless, in the ISA parent survey ( $\left.n=3503\right)$, almost one quarter reported not being counselled or given information about autopsy. Failure to offer autopsy denies parents a chance to understand the cause of their baby's death, increases the proportion of unexplained stillbirths, and hinders the effectiveness of subsequent audit. A critical shortage of perinatal pathologists also hampers efforts. ${ }^{33,}{ }^{34}$ Such a shortage was shown in our surveys, where only $26 \%$ of care providers reported that autopsies were performed or supervised by perinatal or paediatric pathologists. Resources continue to be diverted away from perinatal 
pathology, ${ }^{33,35}$ despite stillbirths and neonatal deaths outnumbering deaths from cancer. ${ }^{9,}{ }^{36}$ In our survey of care providers, only $33 \%$ reported that autopsy was routinely performed upon consent (Figure 3, webappendix). Parental consent and cost were frequently cited barriers to investigations (Figure 4, webappendix), despite evidence that identifying the cause of stillbirth may reduce costs in subsequent pregnancies. As stated by Heazell and colleagues, ${ }^{6}$ the cost of care for subsequent pregnancies following stillbirth with an assigned cause is less than for women whose stillbirths were of unknown cause. ${ }^{37}$

Changes in diagnostic testing may lead to revisions of causes of stillbirths. Chromosomal microarray is now preferred to karyotype since it overcomes the problem of non-viable tissue. Microarrays also identify abnormalities, such as microdeletions and microduplications, that are not identified by karyotyping. ${ }^{38}$ However, adoption of diagnostic advances is slow, with $30 \%$ of care providers from the ISA survey unsure how frequently microarray was performed; only $4 \%$ indicated that microarray was routine. Whichever test is used, it is important to have a perinatal pathology service to determine phenotype to assess the significance of newly described genetic variations..$^{39,40}$

\subsubsection{Addressing data quality in causes of stillbirth}

Classification of cause of death in stillbirth needs to be standardised, especially with regard to placental pathology. Collective agreement of definitions of placental lesions and their significance is also needed. Although the same lesions may be seen in stillbirths and in livebirths, high quality studies suggest that specific placental lesions are significantly more common in cases of stillbirth. ${ }^{41}$ This is also true for other "causes" of stillbirth. In a recent review, not a single classification systems met the criteria of a quality system. ${ }^{42}$ Development of the WHO's International Classification of Diseases Perinatal Mortality (ICD-PM), presented in a commentary to this series, ${ }^{43}$ aims to address this. While HIC are likely to continue with detailed classification based on sophisticated diagnostics not accessible in LMIC, approaches must be consistent with the ICD-PM system, and HIC must reach consensus on such a system. Underpinning accurate data on causes is the availability of thorough 
history and diagnostic testing. Standardised perinatal death datasets are essential. Such datasets are in place nationally in The UK, Ireland and New Zealand, and under pilot-testing in Australia.

\subsection{Understanding and tackling disparities in stillbirth risk}

Disparities reflect larger systems of structural inequality, including racism and systematic inequities in opportunities and power. $^{44}$ Consequently, health disparities reflect social and political determinants rather than biological origin. ${ }^{45}$, ${ }^{46}$ Within HIC, stillbirth rates for disadvantaged groups are often double those of more advantaged groups, and are likely to be underestimated, as health disparities are often only measured by comparing the most advantaged with the least advantaged. ${ }^{47}$ The relationship between stillbirth and social disadvantage is complex, with probable links across preconception, pregnancy pathways and risk factors (Figure 3).

\subsubsection{Access to, and quality of, antenatal and maternity care}

Disadvantaged women are less likely to receive adequate antenatal care. ${ }^{48}$ Access to, and quality of antenatal care also differs by populations served, ${ }^{49}$ and amongst ethnicities. ${ }^{50}$ There are clear and specific circumstances where differential access or uptake of services contributes to disparities. These include antenatal diagnosis and pregnancy termination for congenital anomalies; timely diagnosis and treatment of preeclampsia; and labour induction for post-term pregnancy. Rural-urban differences in access to services are also likely to contribute, especially among vulnerable populations in remote areas. ${ }^{51,52}$ Institutionalised racism is commonly reported by women accessing antenatal care..$^{53}$

\subsubsection{Beyond health care delivery}

Health disparities are only partly explained by disparities in maternity care. ${ }^{47}$ Complex social determinants, termed "causes of the causes", include: poverty; experiences of discrimination; incarceration; addiction; chronic stress; inadequate education, child care, employment, transportation, and living conditions. ${ }^{54}$ Intimate partner violence, ${ }^{55}$ mental health issues, ${ }^{56}$ and the cumulative impact of stressful "life events" ${ }^{57}$ are also hidden but potent risks. In a systematic review 
of nearly 1,000,000 births in The UK from 1993-2005, stillbirth rates were 1.5-2 fold greater between the highest and lowest area deprivation quintiles. ${ }^{58,59}$

In a recent study, women migrating to HIC had stillbirth rates double host country averages, particularly when their country of birth was a humanitarian source country. ${ }^{60}$ Adjusted for age, parity, socioeconomic status and $\mathrm{BMI}$, these differences disappeared, ${ }^{60}$ suggesting ethnicity may not always be a pathway to increased stillbirth. However, disparities in pregnancy outcomes continue between women of differing racial or ethnic background accessing the same healthcare services. ${ }^{61-63}$ Stillbirth rates for women of South Asian and African origin giving birth in Europe or Australia are 2-3 times higher than those of Caucasian women. ${ }^{61-63}$ The challenge is to understand why, and how we can manage the excess risk of stillbirth correlated with ethnicity within routine and comprehensive antenatal care.

\subsubsection{Addressing disparity}

To understand and address socioeconomic disparities in stillbirth, it is critical that all HIC monitor and report SES in vital statistics. ${ }^{12}$ Maternal education is one relevant and feasible indicator for withincountry and cross-country comparisons. ${ }^{12}$ Across 19 European countries with a median population attributable risk of $26 \%$ (IQR 16 to 31), Zeitlin and colleagues showed 1,606 out of 6,447 stillbirths would not have occurred in 2010 if rates for all women were the same as for women with postsecondary education. School completion for pregnant women could therefore have a substantial impact on reducing disparities. Structural issues such as housing, employment and food security policies must also be addressed.

Antenatal care, home visiting services and financing of contraceptive services are examples of interventions with capacity to address reproductive health strategies ${ }^{64}$ and therefore to prevent stillbirths. Universal service platforms should be supplemented with efforts to engage vulnerable populations, including outreach strategies and transportation to health services. In 2011 we nominated quality, accessible, culturally responsive and appropriate preconception care among priorities to reduce disparity. ${ }^{7}$ Improving preconception care remains an enormous challenge. 
Innovative community programs addressing refugee maternal and child health inequalities ${ }^{65}$ and antenatal care programs involving partnerships between midwives and Aboriginal health workers are underway in Australia. ${ }^{66,67}$ Universally, women whose first language differs from dominant national languages should be offered care and information in their own language ${ }^{68}$ with choice of interpreter gender. ${ }^{65}$ The US Affordable Care Act will provide services such as free contraception, screening for infections and alcohol and smoking cessation programs. ${ }^{69}$

\subsection{Quality of care}

\subsubsection{Uptake of interventions in stillbirth prevention}

Through the ISA survey of care providers we assessed uptake and perceived barriers to implementation of LSS recommended interventions in stillbirth prevention (Figures 5 and 6, webappendix). Only $60 \%$ of respondents said they always provided smoking cessation advice. The most frequently cited barriers were lack of time and/or resources (20\%) and acceptance to women (35\%). Only $36 \%$ said they always provided culturally-appropriate care, with lack of time and/or resources the most common barrier (17\%). Serial fundal height measurements were performed not at all or only sometimes by $14 \%$, with $10 \%$ identifying lack of evidence as a barrier. Most providers said they always or mostly used early ultrasound assessment of gestational age (83\%), with cost and acceptance to women cited as barriers by around $12 \%$. Screening for gestational diabetes at 28 weeks was always or mostly performed by $77 \%$, with $12 \%$ citing acceptance by women as a barrier. Use of Doppler velocimetry in high-risk pregnancies had reasonably high usage (68\%), with lack of evidence (11\%) and cost (9\%) the most frequently cited barriers. The least commonly used intervention (used always or mostly by $43 \%$ ) was low dose aspirin for high-risk pregnancies, with $13 \%$ reporting lack of evidence as a barrier. Low dose aspirin and heparins have been used to improve placental function and decrease stillbirth, but a high number needed to treat (aspirin) and uncertain efficacy has prevented widespread adoption of these interventions. ${ }^{70}$ While evidence is limited, preconception care is a potentially valuable intervention in stillbirth prevention, yet only $28 \%$ of care 
providers said that preconception care for women with risk factors was performed mostly/always in their facilities.

\subsubsection{Antenatal and bereavement care - Information, communication and support}

In addition to clinical care, quality maternity care incorporates interpersonal and emotional aspects of care. ${ }^{71}$ Since stillbirth is an indicator of quality care, women's experiences of care around stillbirth can be considered an indicator of quality of care processes. Just as actions can be taken to prevent stillbirth, actions can be taken to prevent adverse psychosocial outcomes following stillbirth and, in both instances, suboptimal interpersonal care can undermine even the best clinical care and produce harm (see Heazell and colleagues). ${ }^{6}$ The ISA surveys asked parents and care providers eight questions designed to capture components of quality care consistently identified as important to women (webappendix). The data (Figure 7, webappendix) show that care providers viewed various aspects of care more positively than bereaved parents. At least 4 in 5 providers $(83-95 \%)$, but only 3 in 5 parents (54-70\%), considered these aspects of quality care to be present always or most of the time. Not spending enough time with parents in antepartum care was a point of agreement for parents and care providers. Critically, more than one-third of parents believed their concerns were not taken seriously or felt not listened to, either before or after their baby was stillborn.

Ratings of information-provision and parental involvement in decision-making after stillbirth were lower for parents and care providers alike compared with before stillbirth, underscoring the challenge of providing quality bereavement care. Parents' views of the comprehensibility of information were also less positive; barely half felt the time spent with care providers was adequate. Many of the questions parents had at this time could be readily answered and procedures to answer such questions would be easy to implement (Panel 1, webappendix). Missed opportunities to answer parents' questions might be avoided by measures that recognise parents' need to know more about their child.

These survey findings corroborate the results of a systematic review on parents' and care providers' experiences of bereavement care. ${ }^{72}$ Care providers were found to "hide" behind ritualising guidelines 
and checklists; they were frequently not trained to expect and manage parents' reactions and individual needs. In our survey of care providers, only $23 \%$ reported being satisfied with training opportunities in bereavement care at their facility, and $30 \%$ had no opportunities. As found in the meta-analysis, care providers urgently need emotional, knowledge and system-based support, and training in verbal and non-verbal communication skills.

\subsubsection{Addressing quality of care}

Stillbirth prevention requires emphasis on quality maternity care that is respectful of a woman's rights and tailored to her needs. ${ }^{71}$ Quality can be improved through better communication and information-provision, and timely delivery of evidence-based interventions. Quality bereavement care must also be emphasised, with greater access to training a crucial first step. Maternity units must decide whether this is best accomplished via training and certification of competencies for all staff, or whether to assign the role of bereavement support to a dedicated group. Access to clinical practice guidelines is imperative, but active implementation and evaluation are required. ${ }^{73}$ The UK provides an extensive range of national clinical guidelines acknowledging every aspect of the key messages of the LSS HIC paper but, for other HIC with a high stillbirth burden, such resources are far less comprehensive (webappendix). Publically available reports of maternal satisfaction with care and other indicators of women's maternity care experiences should be developed, as done in Queensland, Australia, ${ }^{74}$ New Zealand ${ }^{75}$ and across The UK. ${ }^{76}$ Audit and feedback and benchmarking programs that include explicit targets for change and suggestions for how change can be achieved are also effective. ${ }^{77}$

\subsubsection{Perinatal mortality audit - Why and how?}

Perinatal audit has been described as: "The systematic, critical analysis of the quality of perinatal care, including the procedures used for diagnosis and treatment, the use of resources and the resultant outcome and quality of life for women and their babies" ${ }^{78}$ Audits in the Netherlands, ${ }^{79}$ The $\mathrm{UK}^{80}$ and New Zealand ${ }^{11}$ show substandard care factors are present in an unacceptably high proportion of cases (20-30\%, and up to $60 \%$ for intrapartum stillbirths). In New Zealand, stillbirth 
rates at term have declined over the seven years since national perinatal audit began ${ }^{11}$ (Figure 8 , webappendix). This decline was specifically attributed to a reduction in stillbirth at 37-40 weeks' gestation and $\geq 41$ weeks' gestation. Despite their value, few countries have implemented nationallevel perinatal audit programs (webappendix). Norway, which originally introduced it in 1984 , has now abandoned this practice. Among the care providers we surveyed, only $37 \%$ reported that their facility conducts regular perinatal audit meetings; these were most commonly held only monthly (34\%) or quarterly (26\%), and used case discussion only as opposed to formal audit methodology (61\% vs $12 \%)$.

There is a clear need for greater focus on effective, sustainable implementation of perinatal audit to ensure health services identify areas of suboptimal care. Establishing perinatal mortality audit requires both service- and ministerial-level support, and quarantined time for multidisciplinary team engagement. Other critical components include an agreed set of definitions, adoption of a formal audit methodology, and appropriate indicators for monitoring and evaluation, and effective data systems (Panel 2). Innovative e- and $\mathrm{m}$-health solutions currently being implemented hold promise, as well as structured education programs around institutional perinatal mortality audit and classification such as the IMPROVE program. ${ }^{82}$

\subsection{Antenatal screening and interventions to prevent stillbirth - Are we getting closer?}

\subsubsection{Early delivery}

Routine induction of labour (IOL) at term and post-term reduces the risk of perinatal mortality and caesarean birth..$^{83}$ However, birth prior to 39 weeks increases the risk of morbidity ${ }^{84}$ and is associated with increased risk of long-term mortality. ${ }^{85}$ Therefore, prior to 39 weeks, early delivery requires balancing any reduction in stillbirth risk against these risks, and should only be considered in the presence of significant risk for maternal and neonatal complications. When IOL is undertaken, adequate information-provision to women is essential, as women have reported not being aware of 
the risks of induction or the implications for future pregnancies until after the induction had been performed. ${ }^{86}$

The ARRIVE trial ${ }^{87}$ in the US comparing elective IOL at 39 weeks with expectant management among singleton uncomplicated term pregnancies may help to clarify the risks and benefits of term induction.

\subsubsection{Ultrasonic and biochemical prediction of stillbirth risk}

Multiple pathophysiological processes result in stillbirth, making it difficult to predict. ${ }^{88} \mathrm{~A}$ test is likely to perform poorly when assessed against all stillbirths, but possibly more specific for a given cause of stillbirth. A systematic review of biomarker and ultrasonic tests found none of 16 single, or 5 combined, tests performed well as predictors of stillbirth. ${ }^{89}$ However, stillbirth attributed to placental dysfunctional disorders was moderately to strongly associated (positive likelihood ratios between 5 and 15) with low first trimester pregnancy associated plasma protein A (PAPP-A), and abnormal uterine artery Doppler velocimetry in the second trimester. More studies are needed to determine whether closer vigilance or any treatment is effective to prevent stillbirth in this increased-risk group.

\subsubsection{Routine late pregnancy ultrasound to screen for fetal growth restriction}

Of the estimated $30-50 \%$ of stillbirths related to FGR; most are undetected and many occur in women lacking risk factors. ${ }^{90}$ Ultrasonic fetal biometry is widely used in high risk pregnancies as a means of detecting FGR, thus universal ultrasound is one potential approach to screening low-risk women. ${ }^{90}$ However, high-quality evidence on the diagnostic effectiveness of ultrasound is lacking. ${ }^{91} \mathrm{~A}$ recent prospective cohort study found universal scanning was associated with approximately 3-fold increase in the detection of small for gestational age (SGA) (20-57\%). ${ }^{92}$ Further, SGA fetuses with reduced abdominal circumference growth velocity were at increased risk of morbidity, whereas SGA fetuses with normal growth velocity were not. This study confirms universal ultrasound is effective in identifying FGR. However, the costs and potential adverse iatrogenic consequences of implementing such an intervention require consideration..$^{93}$ 


\subsubsection{Challenges in gaining high quality evidence for screening}

Sample size calculations demonstrate that even if a screening test has a positive likelihood ratio of 10 and was coupled with an intervention that reduced stillbirth by $50 \%$, a study of screening and intervention would still require approximately 130,000 women to be adequately powered (Figure 9, webappendix). Possible approaches to address this problem are the inclusion of stillbirth as part of a composite outcome and the use of study designs with randomisation at the hospital level, including cluster randomised controlled trials (RCTs) or stepped wedge $\mathrm{RCTs},{ }^{88}$ such as the trials of fetal movement awareness interventions mentioned below. ${ }^{94,95}$

\subsubsection{Promising antenatal interventions?}

Raising awareness of decreased fetal movements (DFM) may aid stillbirth prevention via timely detection and reporting, though concerns exist over the potential to increase anxiety and health service utilisation. ${ }^{96}$ Two large-scale trials of fetal movement awareness interventions are ongoing in Australasia, ${ }^{95}$ and Ireland and The UK. ${ }^{94}$ In a large non-randomised study, an educational program of standardised measurement of fundal height, plotting on customised charts and referral protocols, has also been associated with reduced stillbirth. ${ }^{97}$ Data from RCTs are required to confirm or refute these findings. ${ }^{98}$ The adverse impact of supine sleep position in late pregnancy has recently been highlighted as a potentially modifiable risk factor. ${ }^{99-102}$ Although these findings are biologically plausible, results from further studies in The $\mathrm{UK}^{103}$ and New Zealand ${ }^{100}$ study are awaited.

\subsection{The research agenda}

The LSS identified 30 questions derived from opinions of professionals and researchers. Research priority setting methods have since developed to include patient and public views. As part of the ISA surveys, over 7,000 parents, care providers and community members provided stillbirth action and research priorities. While the ISA project is ongoing, preliminary data indicate agreement with the

LSS and a recent UK project. ${ }^{104}$ Major topics included: stillbirth prevention by application of current tests and development of novel investigations with optimal timing of delivery, understanding 
placental pathways in stillbirth and the causes of unexplained stillbirth, optimal bereavement care, and subsequent pregnancy care.

Perinatal mortality audit programs, interventions to reduce the prevalence of overweight and obesity, and initiatives to increase the coverage of smoking cessation programs in pregnancy are also priorities. With static rates of stillbirths $<28$ weeks across HIC, and with spontaneous preterm labour and/or preterm ROM a major contributor, ongoing efforts in prediction and prevention of preterm birth are important in stillbirth prevention. Strengthening collaborations between researchers and parents to address priorities using similar protocols is key in addressing stillbirths in HIC.

\subsection{Conclusions}

Stillbirth remains a major public health problem in HIC and reductions in rates have not matched those for neonatal mortality. Variation and socio-economic disparities in stillbirth rates, suboptimal uptake of interventions, low proportions of stillbirths attributed to congenital abnormality and high proportions classified as unexplained, and the contribution of substandard care factors suggest stillbirths are not inevitable, and that further reduction in HIC is possible. Ending preventable stillbirths in HIC can be achieved through improvements in the health status of women, through improvements in quality of maternity care, and by reducing social inequities. High quality perinatal mortality audit informed by thorough investigation is attainable in all HIC and holds the key to (relatively) rapid reductions in stillbirth rates.

The death of a child before birth is a tragedy for families, and stigma and fatalism must be eliminated to optimise bereavement care and to reduce the number of these deaths. 


\subsection{Contributions}

V Flenady was responsible for overall development and writing of the manuscript; A Wojcieszek assisted with development and writing of the manuscript and coordination of author contributions; D Ellwood and P Middleton assisted in editing; V Flenady , A Wojcieszek, D Ellwood, F Boyle, D Horey, A Vanacci, C Ravaldi, J Cassidy, P Cassidy, J F Frøen, L Farrales, M Gross, P Middleton, J J Erwich, G Smith, TY Khong, R M Silver, S Leisher, L McCowan, D Siassakos, A Heazell and S Petersen contributed to the development and dissemination of the web-based surveys; A Wojcieszek coordinated the dissemination of surveys and S Leisher and A Wojcieszek coordinated the survey translations; A Wojcieszek lead the quantitative survey data analyses with V Flenady, M Coory; F Boyle, D Horey, undertook qualitative survey data analysis; J E Lawn and H Blencowe conducted data analyses for stillbirth rates and risk factors; T Y Khong, R M Silver, S Leisher, JJ Erwich developed the diagnostic test section; D Ellwood developed the risk factor and interventions sections; V Flenady, M Coory, and H Reinebrant undertook the causes of stillbirth analysis; JJ Erwich, C Farquar , L Sadler developed the perinatal mortality audit section; P Middleton, L Farrales, S Brown, K S Joseph, J Zeitlin, E Wallace developed the disparity section; D Siassakos, A Heazell , C Storey contributed a meta-synthesis on experiences of bereavement care; G Smith and L McCowan assisted to develop the antenatal screening and interventions to prevent stillbirth section; F Bloomfield, G Smith, J F Frøen, and R Goldenberg contributed to framing and drafting of the manuscript. All authors read and approved the final version of the manuscript.

\subsection{Conflicts of interest}

HB received grants from Saving Newborn Lives, Save the Children, during the conduct of the study. SB received salary support via a Future Fellowship from the Australian Research Council, during the conduct of the study. LS received personal fees from Health Quality and Safety Commission NZ, during the conduct of the study. DS received grants from Sands, outside the submitted work and is a member of the Executive Committee of the Stillbirth Clinical Study Group, UK (RCOG \& Sands), the Department of Health Stillbirth task-and-finish groups, and the PROMPT Maternity Foundation. GS received non-financial support from $\mathrm{GE}$, personal fees and non-financial support from Roche, grants and personal fees from GSK, outside the submitted work. All remaining authors have nothing to disclose.

\subsection{Acknowledgments}

We sincerely thank every parent, care provider and community member who gave their time to complete the ISA web-based surveys. We thank the International Stillbirth Alliance (ISA) Scientific Network, the International Confederation of Midwives (ICM), the International Federation of 
Gynecology and Obstetrics (FIGO), ISA member organisations, and further national organisations that supported the dissemination of surveys. Finally, we thank Translators Without Borders for assisting with survey translations.

\subsection{Funding}

Mater Research Institute - The University of Queensland provided infrastructure and funding for the research team to enable this work to be undertaken. The Canadian Research Chair in Psychosocial Family Health provided funding for revision of the translation of the French web-based survey of care providers. 
1. de Bernis L, Kinney M, Stones W, et al. Stillbirths: Ending preventable deaths by 2030. The Lancet (Submitted) 2015.

2. Frøen JF, Friberg IK, Lawn JE, et al. Stillbirths: Progress and unfinished business. The Lancet (Submitted) 2015.

3. Bradley NM, Lucy KS, Alun Evans T, et al. Perinatal mortality surveillance report UK - Perinatal deaths for births from January to December 2013. Leicester: Department of Health Sciences University of Leicester, 2015.

4. Gregory EC, MacDorman MF. Fetal and Perinatal Mortality: United States, 2013. Natl Vital Stat Rep 2015; 64(8): 1-24.

5. Joseph KS, Kinniburgh B, Hutcheon JA, et al. Determinants of increases in stillbirth rates from 2000 to 2010. CMAJ 2013; 185(8): E345-51.

6. Heazell AE, Siassakos D, Blencowe H, et al. Stillbirths: Why Invest? The Lancet (In Press) 2015. 7. Flenady V, Middleton P, Smith GC, et al. Stillbirths: the way forward in high-income countries. Lancet 2011; 377: 1703-17.

8. Blencowe H, Lawn J. National, regional, and worldwide estimates of stillbirth rates in 2015 with trends since 1995: a systematic analysis. Lancet Global Health (Submitted) 2015.

9. Lawn JE, Blencowe H, Waiswa $\mathrm{P}$, et al. Stillbirths: Data for accelerating progress towards 2030. The Lancet (In Press) 2015.

10. Ibiebele I, Coory M, Boyle FM, et al. Stillbirth rates among indigenous and non-indigenous women in Queensland, Australia: is the gap closing? BJOG: An International Journal of Obstetrics \& Gynaecology 2014: n/a-n/a.

11. PMMRC. Nineth annual report of the Perinatal and Maternal Mortality Review Committee: Reporting mortality 2013. Wellington: Health Quality \& Safety Commission, 2015.

12. Zeitlin J, Mortensen L, Prunet C, et al. Socioeconomic inequalities in stillbirth rates in Europe: measuring the gap using routine data from the Euro-Peristat Project. BMC Pregnancy Childbirth (Submitted to Ending Preventable Stillbirths Supplement) 2015.

13. Mohangoo AD, Buitendijk SE, Szamotulska K, et al. Gestational age patterns of fetal and neonatal mortality in Europe: results from the Euro-Peristat project. PLoS One 2011; 6(11): e24727.

14. Hilder L, Li Z, Zeki R, et al. Stillbirths in Australia 1991-2009. Perinatal statistics. Series no. 29. Cat. no. PER 63. Canberra: AlHW, 2014.

15. Joseph KS, Liu S, Rouleau J, et al. Influence of definition based versus pragmatic birth registration on international comparisons of perinatal and infant mortality: population based retrospective study. BMJ 2012; 344: e746.

16. MacDorman M, Kirmeyer S. Fetal and perinatal mortality, United States, 2005, Natl Vital Stat Rep Natl Vital Stat Rep 2009; 57(8): 1-20.

17. Bukowski R, Carpenter M, Conway D, et al. Causes of death among stillbirths. Jama 2011; 306(22): 2459-68.

18. Froen JF, Cacciatore J, McClure EM, et al. Stillbirths: why they matter. Lancet 2011; 377(9774): 1353-66.

19. Flenady V, Koopmans L, Middleton $\mathrm{P}$, et al. Major risk factors for stillbirth in high-income countries: a systematic review and meta-analysis. The Lancet 2011; 377(9774): 1331-40.

20. Marufu TC, Ahankari A, Coleman T, et al. Maternal smoking and the risk of still birth: systematic review and meta-analysis. BMC Public Health 2015; 15: 239.

21. Mondal D, Galloway TS, Bailey TC, et al. Elevated risk of stillbirth in males: systematic review and meta-analysis of more than 30 million births. BMC Med 2014; 12: 220.

22. Ovesen PG, Jensen DM, Damm P, et al. Maternal and neonatal outcomes in pregnancies complicated by gestational diabetes. a nation-wide study. J Matern Fetal Neonatal Medicine 2015: 15 . 
23. Schummers L, Hutcheon JA, Bodnar LM, et al. Risk of adverse pregnancy outcomes by prepregnancy body mass index: a population-based study to inform prepregnancy weight loss counseling. Obstet Gynecol 2015; 125(1): 133-43.

24. Ramos Salas $X$. The ineffectiveness and unintended consequences of the public health war on obesity. Can J Public Health 2015; 106(2): e79-81.

25. Mulherin K, Miller YD, Barlow FK, et al. Weight stigma in maternity care: women's experiences and care providers' attitudes. BMC Pregnancy Childbirth 2013; 13: 19.

26. Smith $D$, Lavender $T$. The maternity experience for women with a body mass index $\geq 30 \mathrm{~kg} / \mathrm{m2}$ : a meta-synthesis. BJOG: An International Journal of Obstetrics \& Gynaecology 2011; 118(7): 779-89.

27. Froen JF, Pinar H, Flenady V, et al. Causes of death and associated conditions (Codac) - a utilitarian approach to the classification of perinatal deaths. BMC Pregnancy and Childbirth 2009; 9(1): 22.

28. Reinebrant HE, Teoh Z, Leisher SH, et al. Global causes of stillbirth: A systematic review. BMC Pregnancy Childbirth (Submitted to Ending Preventable Stillbirths Supplement) 2015.

29. Ptacek I, Sebire NJ, Man JA, et al. Systematic review of placental pathology reported in association with stillbirth. Placenta 2014; 35(8): 552-62.

30. Ego A, Zeitlin J, Batailler P, et al. Stillbirth classification in population-based data and role of fetal growth restriction: the example of RECODE. BMC Pregnancy Childbirth 2013; 13: 182.

31. Korteweg FJ, Erwich JJ, Timmer A, et al. Evaluation of 1025 fetal deaths: proposed diagnostic workup. Am J Obstet Gynecol 2012; 206(1): 53 e1- e12.

32. Korteweg FJ, Bouman K, Erwich JJ, et al. Cytogenetic analysis after evaluation of 750 fetal deaths: proposal for diagnostic workup. Obstet Gynecol 2008; 111(4): 865-74.

33. Colgan TJ, Geldenhuys L. The Practice of Pathology in Canada: Decreasing Pathologist Supply and Uncertain Outcomes. Arch Pathol Lab Med 2012; 136: 90-4.

34. Robboy SJ, Weintraub S, Horvath AE, et al. Pathologist workforce in the United States: Development of a predictive model to examine factors influencing supply. Archives of Pathology \& Laboratory Medicine 2013; 137(12): 1723-32.

35. PMMRC. Perinatal and Paediatric Pathology Service Provision in New Zealand 2008: Perinatal and Maternal Mortality Review Committee, 2008.

36. Ferlay J, Soerjomataram I, Dikshit R, et al. Cancer incidence and mortality worldwide: Sources, methods and major patterns in GLOBOCAN 2012. International Journal of Cancer 2015; 136(5): E359-E86.

37. Mistry $\mathrm{H}$, Heazell $\mathrm{AE}$, Vincent $\mathrm{O}$, et al. A structured review and exploration of the healthcare costs associated with stillbirth and a subsequent pregnancy in England and Wales. BMC pregnancy and childbirth 2013; 13: 236.

38. Reddy UM, Page GP, Saade GR, et al. Karyotype versus Microarray Testing for Genetic Abnormalities after Stillbirth. New England Journal of Medicine 2012; 367(23): 2185-93.

39. Kooper A, Faas B, Feenstra I, et al. Best diagnostic approach for the genetic evaluation of fetuses after intrauterine death in first, second or third trimester: QF-PCR, karyotyping and/or genome wide SNP array analysis. Molecular Cytogenetics 2014; 7(1): 6.

40. Vrijenhoek T, Kraaijeveld K, Elferink $M$, et al. Next-generation sequencing-based genome diagnostics across clinical genetics centers: implementation choices and their effects. Eur J Hum Genet 2015.

41. Pinar $\mathrm{H}$, Goldenberg RL, Koch MA, et al. Placental findings in singleton stillbirths. Obstetrics and gynecology 2014; $123(2 \mathrm{Pt} 1)$ : 325-36.

42. Leisher SH, Teoh Z, Reinebrant HE, et al. Classification systems for causes of stillbirth and neonatal death, 2009-2014: An assessment of alignment with characteristics for an effective global system. BMC Pregnancy Childbirth (Submitted to Ending Preventable Stillbirths Supplement) 2015. 43. Allanson E, Tunçalp Ö, Chou D, et al. Perinatal mortality: WHO Application of ICD 10 to perinatal deaths. The Lancet (Submitted) 2015. 
44. Dehlendorf C, Harris LH, Weitz TA. Disparities in abortion rates: a public health approach. Am J Public Health 2013; 103(10): 1772-9.

45. Bryant AS, Worjoloh A, Caughey AB, et al. Racial/ethnic disparities in obstetric outcomes and care: prevalence and determinants. Am J Obstet Gynecol 2010; 202(4): 335-43.

46. Dehlendorf C, Bryant AS, Huddleston HG, et al. Health disparities: definitions and measurements. Am J Obstet Gynecol 2010; 202(3): 212-3.

47. Braveman P. Health disparities and health equity: concepts and measurement. Annu Rev Public Health 2006; 27: 167-94.

48. Cha S, Masho SW. Intimate partner violence and utilization of prenatal care in the United States. Journal of Interpersonal Violence 2013.

49. Creanga AA, Bateman BT, Mhyre JM, et al. Performance of racial and ethnic minority-serving hospitals on delivery-related indicators. Am J Obstet Gynecol 2014; 211(6): 647 e1-16.

50. Brett KM, Schoendorf KC, Kiely JL. Differences between black and white women in the use of prenatal care technologies. American Journal of Obstetrics and Gynecology 1994; 170(1): 41-6.

51. Gilbert NL, Auger N, Tjepkema M. Stillbirth and infant mortality in Aboriginal communities in Quebec. Health Rep 2015; 26(2): 3-8.

52. Luo ZC, Wilkins R. Degree of rural isolation and birth outcomes. Paediatr Perinat Epidemiol 2008; 22(4): 341-9.

53. Salm Ward T, Mazul M, Ngui E, et al. "You learn to go last": Perceptions of prenatal care experiences among African-American women with limited incomes. Maternal and Child Health Journal 2013; 17(10): 1753-9.

54. Marmot M. BMA presidency acceptance speech: fighting the alligators of health inequalities; 2010.

55. Mogos MF, Araya WN, Masho SW, et al. The feto-maternal health cost of intimate partner violence among delivery-related discharges in the United States, 2002-2009. Journal of Interpersonal Violence 2014.

56. King-Hele S, Webb RT, Mortensen PB, et al. Risk of stillbirth and neonatal death linked with maternal mental illness: a national cohort study. Arch Dis Child Fetal Neonatal Ed 2009; 94(2): F10510.

57. Hogue $\mathrm{CJ}$, Parker $\mathrm{CB}$, Willinger $\mathrm{M}$, et al. A population-based case-control study of stillbirth: the relationship of significant life events to the racial disparity for African Americans. Am J Epidemiol 2013; 177(8): 755-67.

58. Seaton SE, Field DJ, Draper ES, et al. Socioeconomic inequalities in the rate of stillbirths by cause: a population-based study. BMJ Open 2012; 2(3).

59. Weightman AL, Morgan HE, Shepherd MA, et al. Social inequality and infant health in the UK: systematic review and meta-analyses. BMJ Open 2012; 2(3).

60. Gibson-Helm ME, Teede $\mathrm{HJ}$, Cheng $\mathrm{IH}$, et al. Maternal health and pregnancy outcomes comparing migrant women born in humanitarian and nonhumanitarian source countries: a retrospective, observational study. Birth 2015; 42(2): 116-24.

61. Khalil A, Rezende J, Akolekar R, et al. Maternal racial origin and adverse pregnancy outcome: a cohort study. Ultrasound Obstet Gynecol 2013; 41(3): 278-85.

62. Ravelli AC, Tromp M, Eskes M, et al. Ethnic differences in stillbirth and early neonatal mortality in The Netherlands. J Epidemiol Community Health 2011; 65(8): 696-701.

63. Drysdale $\mathrm{H}$, Ranasinha $\mathrm{S}$, Kendall $\mathrm{A}$, et al. Ethnicity and the risk of late-pregnancy stillbirth. Med J Aust 2012; 197(5): 278-81.

64. Mehta P. Addressing reproductive health disparities as a healthcare management priority: pursuing equity in the era of the Affordable Care Act. Current Opinion in Obstetrics and Gynecology 2014; 26(6): 531-8.

65. Yelland J, Riggs E, Szwarc J, et al. Bridging the Gap: using an interrupted time series design to evaluate systems reform addressing refugee maternal and child health inequalities. Implement Sci 2015; 10(1): 62. 
66. Brown SJ, Weetra D, Glover K, et al. Improving Aboriginal women's experiences of antenatal care: findings from the Aboriginal families study in South Australia. Birth 2015; 42(1): 27-37.

67. Middleton PF, Brown SJ, Bubner TK, et al. The SA Aboriginal Family Birthing Program - a success story. PSANZ: Melbourne April 2015.

68. Boerleider A, Wiegers T, Mannien J, et al. Factors affecting the use of prenatal care by nonwestern women in industrialized western countries: a systematic review. BMC Pregnancy and Childbirth 2013; 13(1): 81.

69. Adams EK, Markowitz S, Dietz PM, et al. Expansion of Medicaid covered smoking cessation services: maternal smoking and birth outcomes. Medicare Medicaid Res Rev 2013; 3(3).

70. Duley L, Henderson-Smart DJ, Meher S, et al. Antiplatelet agents for preventing preeclampsia and its complications. Cochrane Database Syst Rev 2007; (2): CD004659.

71. Renfrew MJ, McFadden A, Bastos MH, et al. Midwifery and quality care: findings from a new evidence-informed framework for maternal and newborn care. The Lancet 2014; 384(9948): 1129-45.

72. Ellis A, Chebsey C, Storey C, et al. Systematic review to understand and improve care after stillbirth: a review of parents and healthcare professionals experiences. BMC Pregnancy Childbirth (Submitted to Ending Preventable Stillbirths Supplement) 2015.

73. Michie S, van Stralen M, West R. The behaviour change wheel: A new method for characterising and designing behaviour change interventions. Implementation Science 2011; 6(1): 42.

74. Prosser SJ, Miller YD, Armanasco A, et al. Findings from the Having a Baby in Queensland Survey, 2012. Brisbane: Queensland Centre for Mothers \& Babies, The University of Queensland, 2013.

75. New Zealand Ministry of Health. Maternity Consumer Surveys 2011. Wellington: Ministry of Health, 2012.

76. Redshaw M, Rowe R, Henderson J. Listening to Parents after stillbirth or the death of their baby after birth. Oxford: National Perinatal Epidemiology Unit, 2014.

77. Ivers N, Jamtvedt G, Flottorp S, et al. Audit and feedback: effects on professional practice and healthcare outcomes. Cochrane Database of Systematic Reviews, 2012.

http://onlinelibrary.wiley.com/doi/10.1002/14651858.CD000259.pub3/abstract (accessed.

78. Dunn PM, Mcllwaine G. Perinatal audit: a report produced for the European Association of Perinatal Medicine. New York, NY: Parthenon; 1996.

79. Eskes M, Waelput AJM, Erwich JJ, et al. Term perinatal mortality audit in the Netherlands 2010-2012: a population based cohort study. BMJ Open 2014; 4: e005652.

80. West Midlands Perinatal Institute. Confidential enquiry into intrapartum related deaths: NHS Perinatal Institute, 2010.

81. Frøen JF, Flenady V, Myhre S, et al. Electronic health registries for mothers and their children. Lancet Global Health (Invited submission in conjunction with Ending Preventable Stillbirth series) 2015.

82. Gardiner $\mathrm{P}$, Kent AL, Rodriguez V, et al. IMproving Perinatal Mortality Review and Outcomes Via Education; An international educational program for health care professionals on best practice around the time of a perinatal death. BMC Pregnancy Childbirth (Submitted to Ending Preventable Stillbirths Supplement) 2015.

83. Gulmezoglu AM, Crowther CA, Middleton P, et al. Induction of labour for improving birth outcomes for women at or beyond term. CochraneDatabase of Systematic Reviews 2012; (6).

84. Spong $\mathrm{CY}$, Mercer BM, D'Alton M, et al. Timing of indicated late-preterm and early-term birth. Obstetrics \& Gynecology 2011; 118(2, Part 1): 323-33.

85. Crump C, Sundquist K, Winkleby MA, et al. Early-term birth (37-38 weeks) and mortality in young adulthood. Epidemiology 2013; 24(2): 270-6.

86. Moore JE, Low LK, Titler MG, et al. Moving toward patient-centered care: Women's decisions, perceptions, and experiences of the induction of labor process. Birth 2014; 41(2): 138-46.

87. Eunice Kennedy Shriver National Institute of Child Health and Human Development (NICHD). Induction in nulliparous women at 39 weeks to prevent adverse outcomes: a randomized controlled 
trial. In: ClinicalTrials.gov [Internet] [cited 28th April 2015]; Bethesda (MD): National Library of Medicine (US)]. Available from: https://clinicaltrials.gov/ct2/show/NCT01990612: NCT01990612. 88. Hussey MA, Hughes JP. Design and analysis of stepped wedge cluster randomized trials. Contemporary Clinical Trials 2007; 28(2): 182-91.

89. Conde-Agudelo A, Bird S, Kennedy SH, et al. First- and second-trimester tests to predict stillbirth in unselected pregnant women: a systematic review and meta-analysis. BJOG 2015; 122(1): 41-55.

90. Rodger MA, Carrier M, Le Gal G, et al. Meta-analysis of low-molecular-weight heparin to prevent recurrent placenta-mediated pregnancy complications. Blood 2014; 123(6): 822-8.

91. National Collaborating Centre for Women's and Children's Health. NICE Guideline: Antenatal care. London: RCOG Press; 2008.

92. Sovio U, Smith G, Dacey A, et al. 151: Screening for fetal growth restriction (FGR) using universal third trimester ultrasonography: a prospective cohort study of 3,977 nulliparous women. American Journal of Obstetrics \& Gynecology; 212(1): S92.

93. Monier I, Blondel B, Ego A, et al. Poor effectiveness of antenatal detection of fetal growth restriction and consequences for obstetric management and neonatal outcomes: a French national study. BJOG 2015; 122(4): 518-27.

94. Eunice Kennedy Shriver National Institute of Child Health and Human Development (NICHD). Promoting awareness fetal movements to reduce fetal mortality stillbirth, a stepped-wedge cluster randomised trial. (AFFIRM). In: ClinicalTrials.gov [Internet] [cited 30th April 2015]; Available from: https://www.clinicaltrials.gov/ct2/show/NCT01777022: NCT01777022.

95. National Health and Medical Research Council of Australia. My Baby's Movements: a stepped wedge cluster randomised controlled trial to raise maternal awareness of fetal movements during pregnancy. In: Australian and New Zealand clinical trials registry [Internet] [cited 30th April 2015]; Available from: https://www.anzctr.org.au/Trial/Registration/TrialReview.aspx?id=365867: ACTRN12614000291684.

96. Mangesi L, Hofmeyr GJ, Smith V. Fetal movement counting for assessment of fetal wellbeing. Cochrane Database of Systematic Reviews 2007, Issue 1 Art No: CD004909 DOI: 101002/14651858.

97. Gardosi J, Giddings S, Clifford S, et al. Association between reduced stillbirth rates in England and regional uptake of accreditation training in customised fetal growth assessment. BMJ Open 2013; 3: e003942.

98. Carberry Angela E, Gordon A, Bond Diana M, et al. Customised versus population-based growth charts as a screening tool for detecting small for gestational age infants in low-risk pregnant women. Cochrane Database of Systematic Reviews 2014, Issue 5 Art No: CD008549 DOI: $101002 / 14651858$.

99. Gordon A, Raynes-Greenow C, Bond D, et al. Sleep Position, Fetal Growth Restriction, and Late-Pregnancy Stillbirth. Obstetrics \& Gynecology 2015; 125(2): 347-55.

100. McCowan LME, Thompson JMD, Cronin R, et al. Supine sleep position in late pregnancy is associated with increased risk of late stillbirth. The International Conference on Stillbirth, SIDS and Baby Survival 2014 Amsterdam, 18-21 September; 2014.

101. Owusu JT, Anderson FJ, Coleman J, et al. Association of maternal sleep practices with preeclampsia, low birth weight, and stillbirth among Ghanaian women. International Journal of Gynecology \& Obstetrics 2013; 121(3): 261-5.

102. Stacey T, Thompson JMD, Mitchell EA, et al. Antenatal care, identification of suboptimal fetal growth and risk of late stillbirth: Findings from the Auckland Stillbirth Study. Australian and New Zealand Journal of Obstetrics and Gynaecology 2012; 52(3): 242-7.

103. Platts J, Mitchell EA, Stacey T, et al. The Midland and North of England Stillbirth Study (MiNESS). BMC Pregnancy and Childbirth 2014; 14(1): 171.

104. Heazell AEP, Whitworth MK, Whitcombe J, et al. Research Priorities for Stillbirth: Process Overview and Results from the UK Stillbirth Priority Setting Partnership. Ultrasound in Obstetrics \& Gynecology 2015. 
105. MacDorman MF. Race and ethnic disparities in fetal mortality, preterm birth, and infant mortality in the United States: an overview. Semin Perinatol 2011; 35(4): 200-8.

106. Zhang S, Cardarelli K, Shim R, et al. Racial disparities in economic and clinical outcomes of pregnancy among medicaid recipients. Maternal and Child Health Journal 2013; 17(8): 1518-25.

107. Auger N, Park AL, Zoungrana $\mathrm{H}$, et al. Rates of stillbirth by gestational age and cause in Inuit and First Nations populations in Quebec. CMAJ 2013; 185(6): E256-62. 


\section{Panels}

Panel 1. Methods

\section{ISA web-based surveys}

We developed three web-based, multilanguage surveys of bereaved parents, care providers and general community members to assess practices around stillbirth prevention, awareness of stillbirth risk factors, quality of antepartum and bereavement care, uptake of stillbirth investigations, audit and classification of stillbirths and more. A mix of categorical items, open-ended items, ranking items and rating scales were included. Surveys were disseminated chiefly via the International Stillbirth Alliance (ISA) member organisations and additional relevant professional societies between December 2014 and February 2015. Surveys were available in English, Dutch, German, Italian, Spanish and Portuguese. The survey of care providers was also available in French and Japanese. In total, 6,636 responses were received across 32 HIC. Quantitative data were analysed in SPSS and were weighted to account for uneven distribution of responses across countries (see webappendix). Qualitative data were sorted in NVivo.

Surveys were approved by the Mater Health Services Human Research Ethics Committee, within the guidelines of the Australian National Statement on Ethical Conduct in Human Research and the University of British Columbia Office Of Research Ethics.

\section{Stillbirth rates in HIC / analysis of avoidable deaths}

The number of potentially preventable stillbirths across all HIC for the year 2015 was calculated from stillbirth rates and total births in Blencowe and colleagues ${ }^{8}$ by subtracting the anticipated numbers of stillbirths applying the 2015 stillbirth rates from the numbers derived using a rate of 2/1000 births for all countries with a rate above $2 / 1000$.

\section{Summary of disparities in HIC}

Socioeconomic disparities in stillbirth rates in HIC were investigated via narrative review, by searching for papers on health inequities and social disadvantage as they relate to stillbirth, by snowballing from those papers, and from citations made to the LSS HIC paper. ${ }^{7}$ We also contacted experts in the field for details of programs addressing disparities in stillbirth and ways of reducing stillbirths in HIC. 
Review of national policies and clinical practice guidelines

National policies on perianal mortality audit

We searched for policies national policies on perinatal mortality audit across the top 36 HIC according to number of annual stillbirths (equating to $99 \%$ of the known stillbirth burden in HIC). Perinatal audit was defined as per Dunn and Mcllwaine as "The systematic, critical analysis of the quality of perinatal care, including the procedures used for diagnosis and treatment, the use of resources and the resultant outcome and quality of life for women and their babies" ${ }^{78}$ Specifically, we searched for policies for national perinatal data collection that is coupled with mandatory indepth review of care by a multidisciplinary team following a stillbirth (see webappendix for further search details). We also consulted a local key informant to confirm findings and gain further information.

\section{National clinical practice guidelines}

National clinical practice guidelines and recommendations addressing stillbirth prevention and investigations were identified across the top five developed countries according to number of annual stillbirths (Russian Federation; United States, Japan, France, The United Kingdom). Guidelines of interest included those addressing the key messages of the 2011 LSS HIC paper, ${ }^{7}$ namely overweight and obesity, alcohol and substance use, smoking cessation, training of health professionals to provide care to disadvantaged pregnant women, and stillbirth investigations protocols to assess cause of death. A structured search was conducted specific for each country using a customised list of organisational websites providing national health care guidelines (see webappendix for further search details). We also consulted a local key informant. 
- Execute an information-plan to ensure it is known that stillbirths are not inevitable and that many stillbirths can be prevented by increasing quality of care, particularly around term.

- Obtain support and budget from national bodies, including ministries of health and professional colleges.

- Develop a national network to coordinate the data collection and identify missing cases through a check system using births and death certificate; and to lead timely reporting and analysis.

- Establish a national multidisciplinary leadership/steering group to drive the process, agree on national priorities, develop and monitor formal audit-methodology, establish consistent and robust definitions, ensure consistency across jurisdictions, and ensure perinatal audit remains on the national agenda while it remains relevant.

- Identify clinical champion(s) at service delivery level.

- Develop a system for clinical and process data collection, preferably web-based, to be completed by the clinical staff.

- Ensure that the underlying philosophy of data collection is based on shared ownership of the data to optimise data quality. This includes the ability of units to access their own data in a format that they can use for their own surveillance and perinatal mortality reviews.

- Allocate human resources to support local or regional audit initiatives.

- Conduct local review of perinatal cases with multidisciplinary teams that have allocated time.

- Develop a method to provide useful, automatically-generated feedback to clinicians and facilities of the suggested improvements to support local quality and audit processes.

- Conduct effective monitoring and evaluation of the audit program with relevant and feasible performance indicators.

- Implement processes to ensure that disclosure of information cannot be used for disciplinary action.

- Ensure there is support/funding to support implementation of recommendations. 


\section{Figures}

Figure 1. Current stillbirth rates and reductions since 2000 in HIC

$$
\text { aRR Stillbirth rate 2000-2015 (\%) — Stillbirth rate } 2015 \text { ( } \geq 28 \text { week definition) }
$$

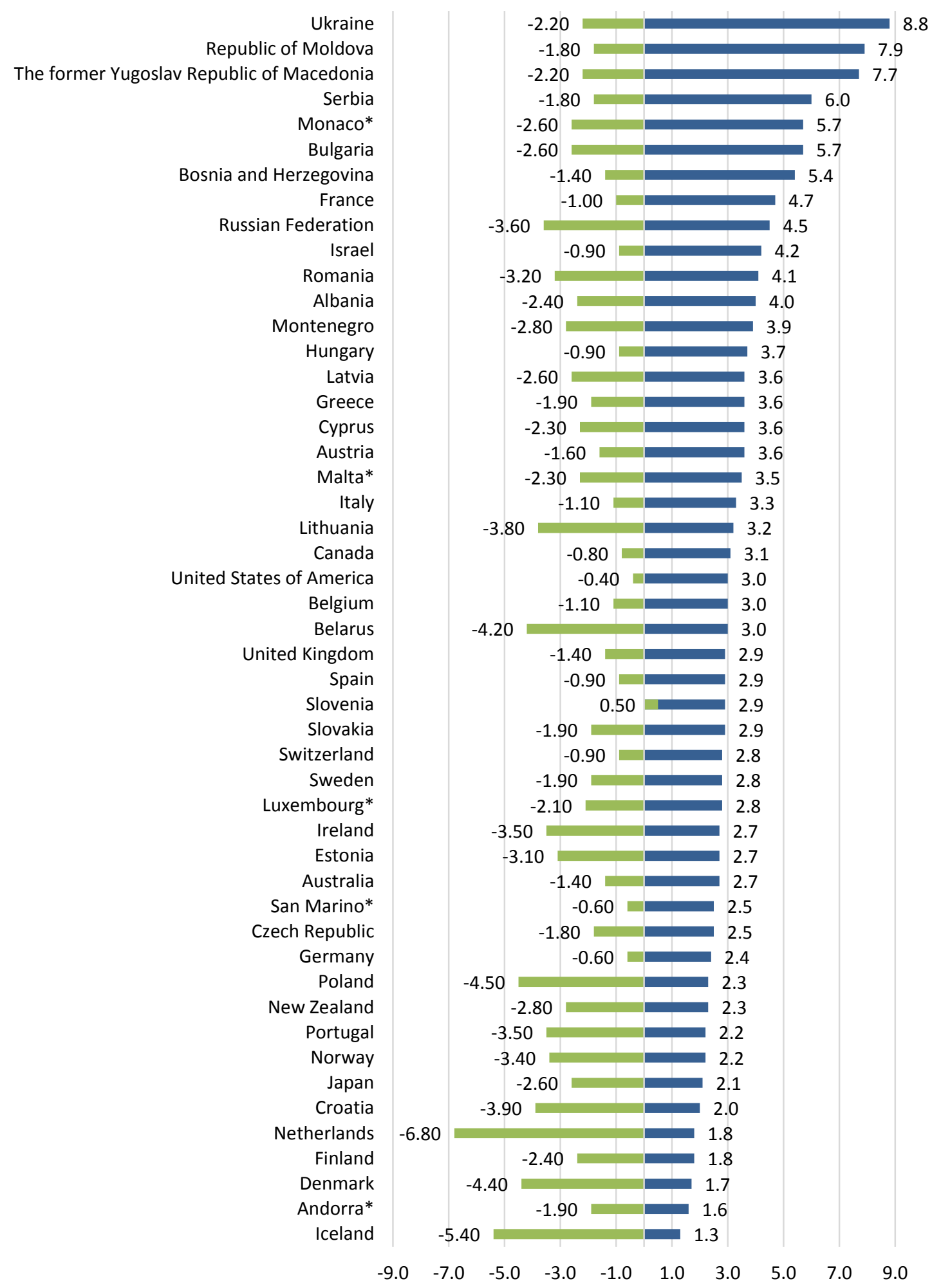

ARR: Annual rate reduction *Countries with $<5000$ annual births 
Figure 2. Survey data on perceptions of stillbirth in high-income countries

"In the community I live/work, people/my colleagues generally think that:"

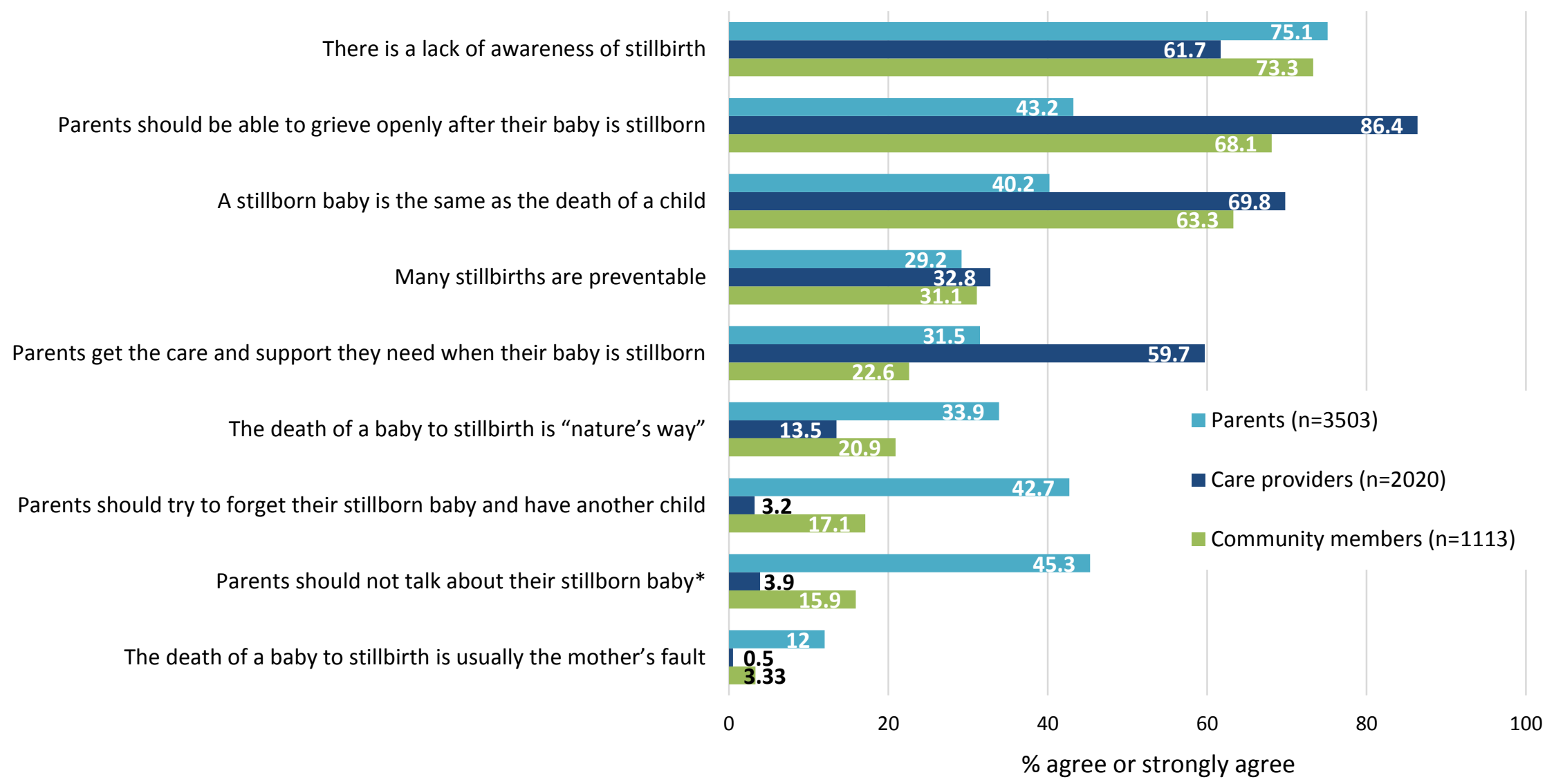

*Full statement: "Parents should not talk about their stillborn baby because it makes people feel uncomfortable" 


\section{Social disadvantage and stillbirth: DOUBLE the risk}
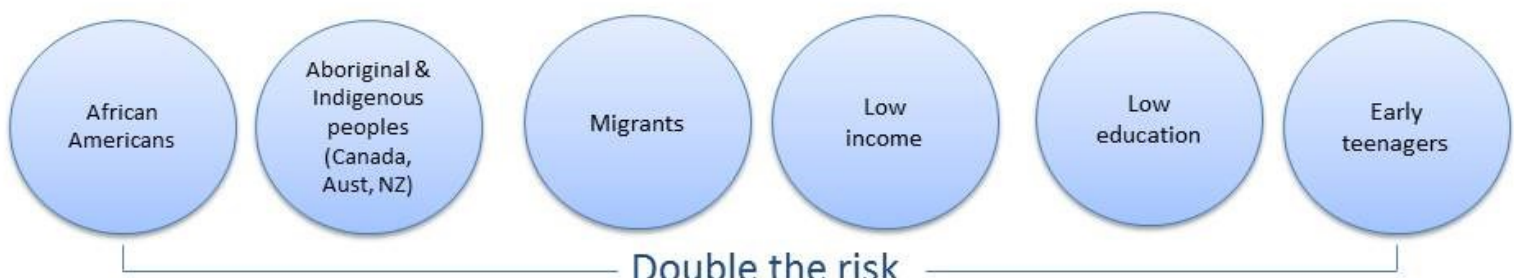

Double the risk
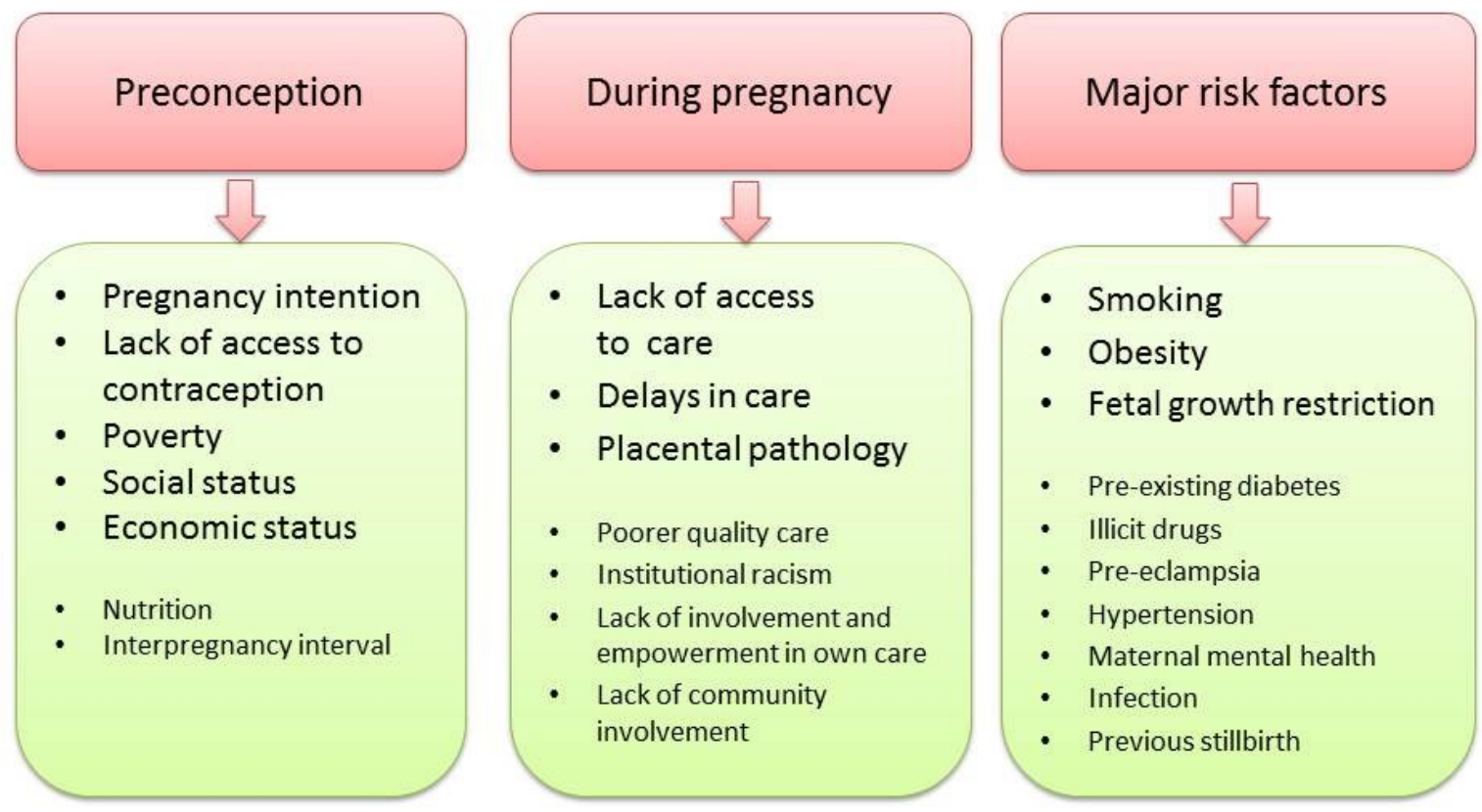

Figure depicts complex relationships and associations for social disparity in stillbirth rates. Stillbirth rates can be double for African-American women; ${ }^{105,106}$ Aboriginal and Indigenous women in Canada, Australia and New Zealand; ${ }^{10,51,107}$ women who have migrated, especially those coming as humanitarian entrants/asylum seekers or refugees; ${ }^{60,107}$ low income women; $;^{58}$ women with low educational achievement; $;^{12}$ and teenage women under 15 years. ${ }^{105}$ 